\title{
INCIDENCE OF INFECTIOUS DISEASE IN THE FIRST THREE YEARS OF LIFE, RELATED TO SOCIAL CIRCUMSTANCES
}

\author{
BY
}

\author{
C. R. LOWE and THOMAS MCKEOWN \\ From the Department of Social Medicine, University of Birmingham
}

The association between the incidence of morbidity in the first 2 years of life and social class (defined according to the occupation of the father) has been examined in two recent communications. Using data for Luton, Grundy (1949) reported no association between "social class" and morbidity; using data from a National sample, Douglas (1951) noted a consistent social gradient in the incidence of disease.

The results of these inquiries have evoked some discussion of differences, which are not in fact very great. Douglas's generalization about a social gradient in morbidity rested mainly on an association in the first 2 years of life between the incidence of lower respiratory infection and occupation of father. The Luton investigation has since been extended to cover the first 5 years (Dykes, Grundy, and LewisFaning, 1953), and it has been concluded that although there was no consistent association between "social class" and the incidence of illness, "the respiratory infections show an upward gradient for the first year of life". Data presented by these authors in their Tables indicate that a similar gradient existed for the first 2 years combined. What seems clear is that, in some parts of Great Britain at least, the relationship of "social class" with morbidity in infancy is not very striking, and the much sharper association with mortality must be attributed largely to differences in case-mortality.

But it by no means follows from this that the incidence of morbidity in infancy is no longer much affected by the environment. There are reasons for doubting whether in this context the occupation of the father provides a sufficiently sensitive index of social circumstances (much less of environment in general); the most important reason is perhaps that it takes no account of family size. Gibson and McKeown (1952) showed that infant mortality in Birmingham in 1947 was more sharply related to maternal age and birth rank than to the standard of housing in the wards in which infants were domiciled. These differences were almost wholly attributable to deaths from infectious disease; for example, among children of mothers aged less than 25 years, the incidence of death from infection between the second and twelfth months was under twenty (per 1,000 children alive at 1 month) in the first born, and over eighty in the fourth and later born.

The magnitude of the differences in mortality made it seem worth exploring the association between morbidity and maternal age and birth rank. Data for this purpose were obtained shortly before or after the third birthday from mothers of certain children born in Birmingham during 1947 (the selection of this sample has been described by Lowe and Gibson, 1953). Each mother was asked to provide details of her child's illnesses during the first 3 years of life, but attention is here restricted to specific infections of childhood, including pneumonia, diarrhoea and vomiting, and otitis media. Diarrhoea and vomiting are included only if a medical practitioner was consulted. Bronchitis and coryza are excluded.

Histories were recorded in respect of 1,782 children (77 per cent. of the original sample). In 39 cases data were incomplete, and the examination of morbidity which follows is based on 1,743 children.

TABLE I

NUMBER OF INFECTIOUS EPISODES (PER 100 CHILDREN) BY THE FIRST AND THIRD BIRTHDAYS

\begin{tabular}{|c|c|c|c|c|c|}
\hline \multirow{3}{*}{ Ward Group } & \multirow{3}{*}{$\begin{array}{l}\text { No. of } \\
\text { Children } \\
\text { at Risk }\end{array}$} & \multicolumn{4}{|c|}{ No. of Episodes per 100 Children } \\
\hline & & \multicolumn{2}{|c|}{ By First Birthday } & \multicolumn{2}{|c|}{ By Third Birthday } \\
\hline & & No. & Per cent. & No. & Per cent. \\
\hline I & 708 & 254 & $35 \cdot 9$ & 762 & $107 \cdot 6$ \\
\hline II and III & 1,035 & 311 & $30 \cdot 0$ & 1,052 & $101 \cdot 6$ \\
\hline Total & 1,743 & 565 & $32 \cdot 4$ & 1,814 & $104 \cdot 1$ \\
\hline
\end{tabular}

We may first note that, as in the two investigations referred to above, the incidence of infectious disease does not appear to be sharply related to social circumstances. Table I gives the number of infectious episodes (per 100 children) by the first and third birthdays, according to Ward Group.*

* As indicated by Gibson and McKeown, 1952, all births in the city in 1947 were assigned by place of domicile to one of three Ward 
In the examination which follows, Ward Group I (poorest standard of housing) is compared with Groups II and III combined. At each interval the incidence of infection is higher, but not very much higher, in Group I than it is in Groups II and III. On the other hand, mortality is much more sharply associated with Ward Group, the number of deaths from infection between 2 and 12 months being $19 \cdot 6$ (per 1,000 children alive at 1 month) in Group $I$, and 11.0 in Groups II and III combined.

Fig. 1 relates mortality, and Fig. 2 morbidity, to birth rank and Ward Group; morbidity is again recorded as the number of infectious episodes (per 100 children) during the first 3 years, numbers being too small to permit separate consideration of the first year. The incidence of both mortality and morbidity rises sharply with birth order; but while Ward Group differences in mortality are substantial at each birth rank, differences in morbidity, though consistent, are trivial.

In Figs 3 and 4 (opposite), Ward Groups are again separated, and the association with birth order is shown separately for the two maternal age groups, under 30 years, and 30 years and over.* It will be noted that both mortality and morbidity

(a) increase with increasing birth rank

(b) decrease with increasing maternal age.

The effect of separation by age and birth order has therefore been further to magnify differences, which even in morbidity are now substantial. For example, in Group I the incidence of infectious episodes is 66 in the first born children of mothers aged 30 and over, and 145 in the third and later born children of mothers under 30 . The corresponding figures for Ward Groups II and III combined are 58 and 152 respectively, which indicates that by comparison with those related to age and birth order, differences associated with the standard of housing are trivial.

Although numbers of children with individual illnesses are rather small, they are large enough in the case of the more common infectious diseases to enable us to examine separately their association

* Maternal age is the age of the mother at the birth of her child.

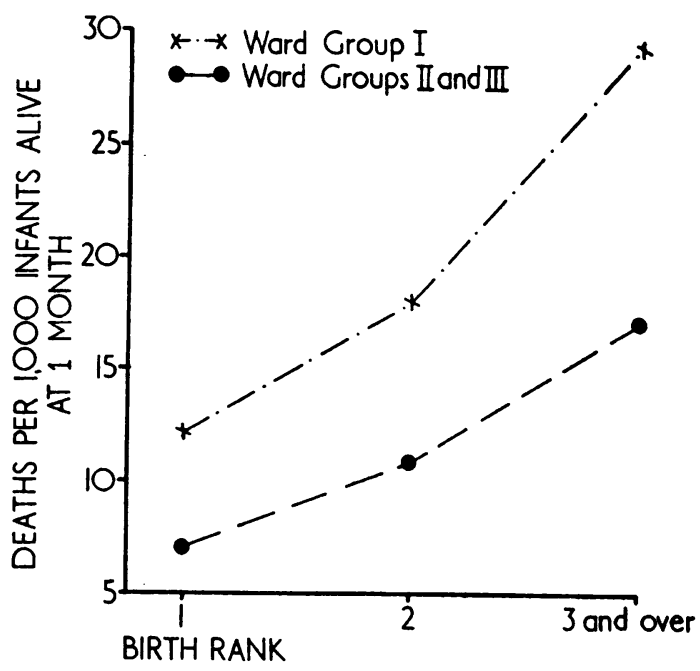

Fig. 1.-Mortality from infection in the second to twelfth months of life, by birth rank and ward group.

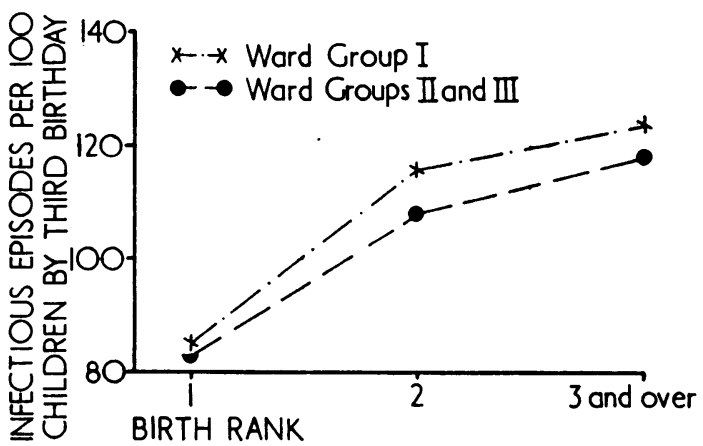

Fig. 2.-Incidence of infection in the first 3 years of life, by birth rank and ward group.

with the same variables. Table II gives the number of infectious episodes in the first 3 years attributed to measles, whooping cough, pneumonia, and diarrhoea and vomiting. The incidence of three of these diseases is a little higher in the Group with the poorest housing (Ward Group I) than in the other two; but in the case of whooping cough the relationship is reversed.

TABLE II

NUMBER OF EPISODES FROM CERTAIN INFECTIONS (PER 100 CHILDREN) BY THE THIRD BIRTHDAY

\begin{tabular}{|c|c|c|c|c|c|c|c|c|c|}
\hline \multirow[t]{2}{*}{ Ward Group } & \multirow{2}{*}{$\begin{array}{l}\text { No. of Children } \\
\text { at Risk }\end{array}$} & \multicolumn{2}{|c|}{ Measles } & \multicolumn{2}{|c|}{ Whooping Cough } & \multicolumn{2}{|c|}{ Pneumonia } & \multicolumn{2}{|c|}{$\begin{array}{l}\text { Diarrhoea and } \\
\text { Vomiting }\end{array}$} \\
\hline & & No. & Per cent. & No. & Per cent. & No. & Per cent. & No. & Per cent. \\
\hline I & 708 & 254 & $35 \cdot 9$ & 160 & $22 \cdot 6$ & 79 & $11 \cdot 2$ & 48 & $6 \cdot 8$ \\
\hline II and III & 1,035 & 334 & $32 \cdot 3$ & 267 & $25 \cdot 8$ & 97 & $9 \cdot 4$ & 35 & $3 \cdot 4$ \\
\hline Total & 1,743 & 588 & $33 \cdot 7$ & 427 & $24 \cdot 5$ & 176 & $10 \cdot 1$ & 83 & $4 \cdot 8$ \\
\hline
\end{tabular}




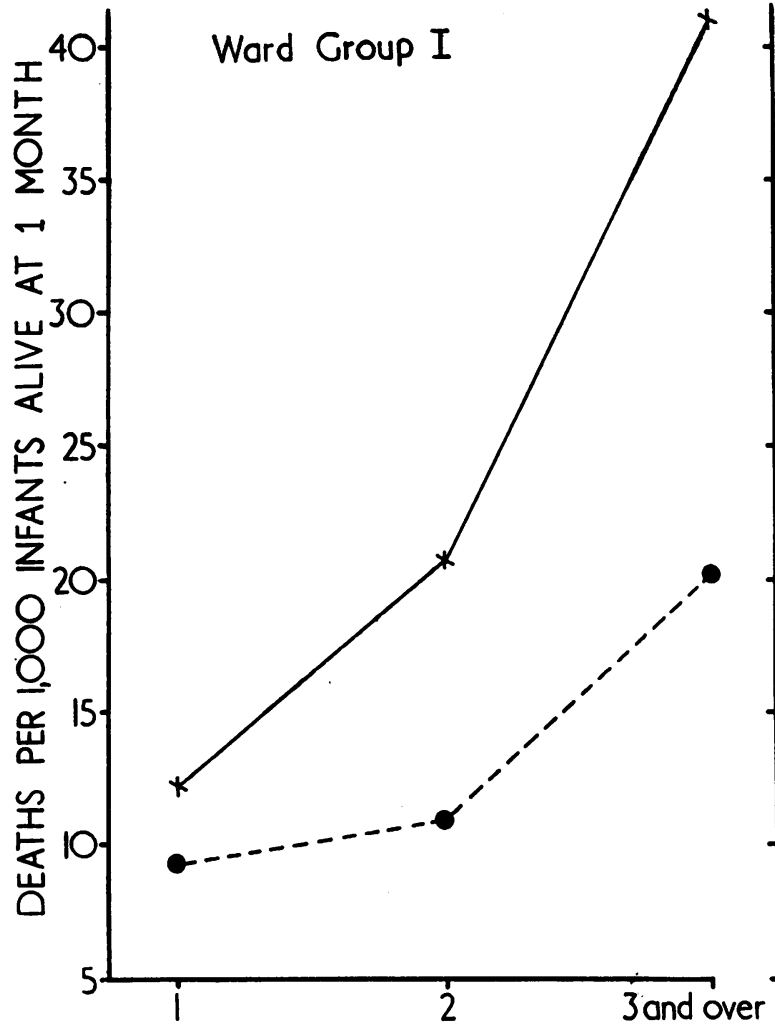

Ward Groups II and III

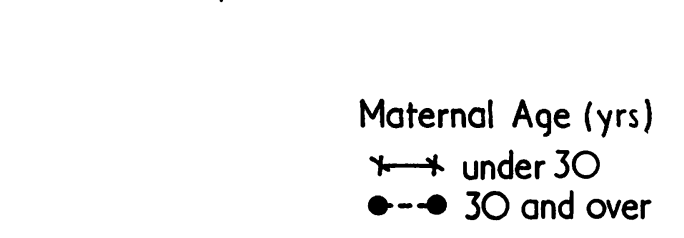

BIRTH RANK

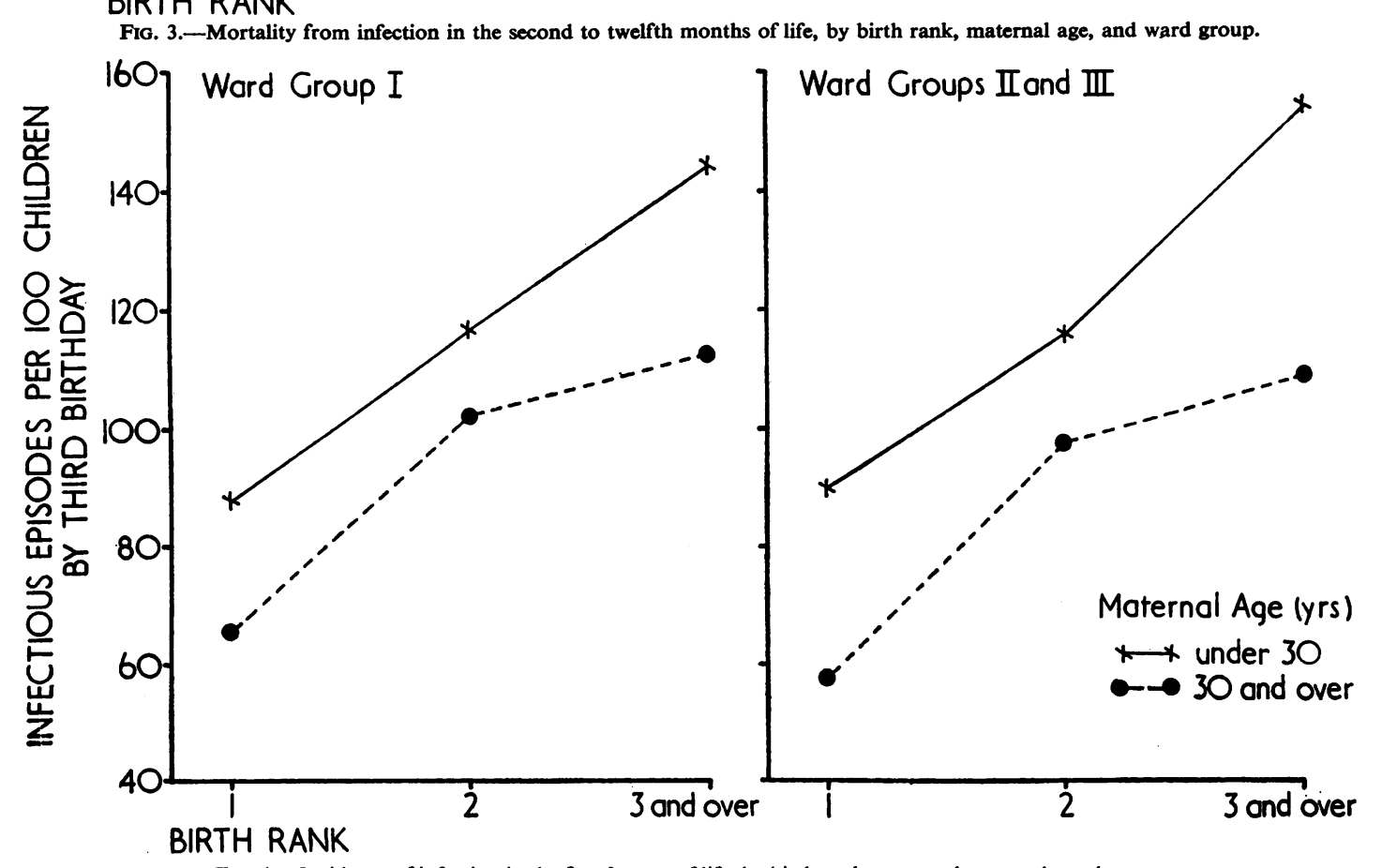

Fig. 4.- Incidence of infection in the first 3 years of life, by birth rank, maternal age, and ward group. 
Fig. 5 relates the incidence of the same infections to maternal age and birth order. In all four diseases, incidence increases with increasing birth order, and is lower for older than for younger mothers, the association is particularly marked for measles, which is more than three times more common among the third and later born children of mothers aged less than 30 than among the first born children of mothers aged 30 and over. The results therefore confirm for individual infections the conclusion previously noted, namely that incidence is more sharply related to birth rank and maternal age than to social circumstances identified according to general standard of housing in the area in which children live.

\section{Discussion}

The data draw attention to certain limitations of "Social Class" as an index of environmental circumstances. It may therefore be worth while to consider briefly the use currently made in vital statistics of "Occupation". On the one hand it is used to establish risks associated with certain kinds of employment, as for example in the estimation of an occupational mortality index. But occupation is also used less directly as a basis of classification according to social circumstances, and it is with this indirect use that we are here concerned.

The Registrar General identifies five "Social Classes" by means of "Occupation", and numerous ad hoc inquiries have adopted the same convention. The difficulty has been to decide upon the best grouping of occupations, which has varied somewhat according to the interests of the investigator. As a rule however, the intention has been to classify according to income, and for this purpose occupation was perhaps as useful as any of the available indices.

As long as gross differences in mortality, and presumably in morbidity also, existed in association with "Social Class", they could be demonstrated without consideration of other variables, of which the most important is undoubtedly family size. But recent investigations indicate that, in parts of Great Britain at least, sharp differences in infant morbidity are not now associated with "Social Class", and the substantial differences in mortality have been attributed, we believe correctly, to differences in case-mortality (Dykes, 1950).

It need hardly be said that it is unwarranted to conclude that the incidence of morbidity in infancy is no longer related to environment. "Social Class"

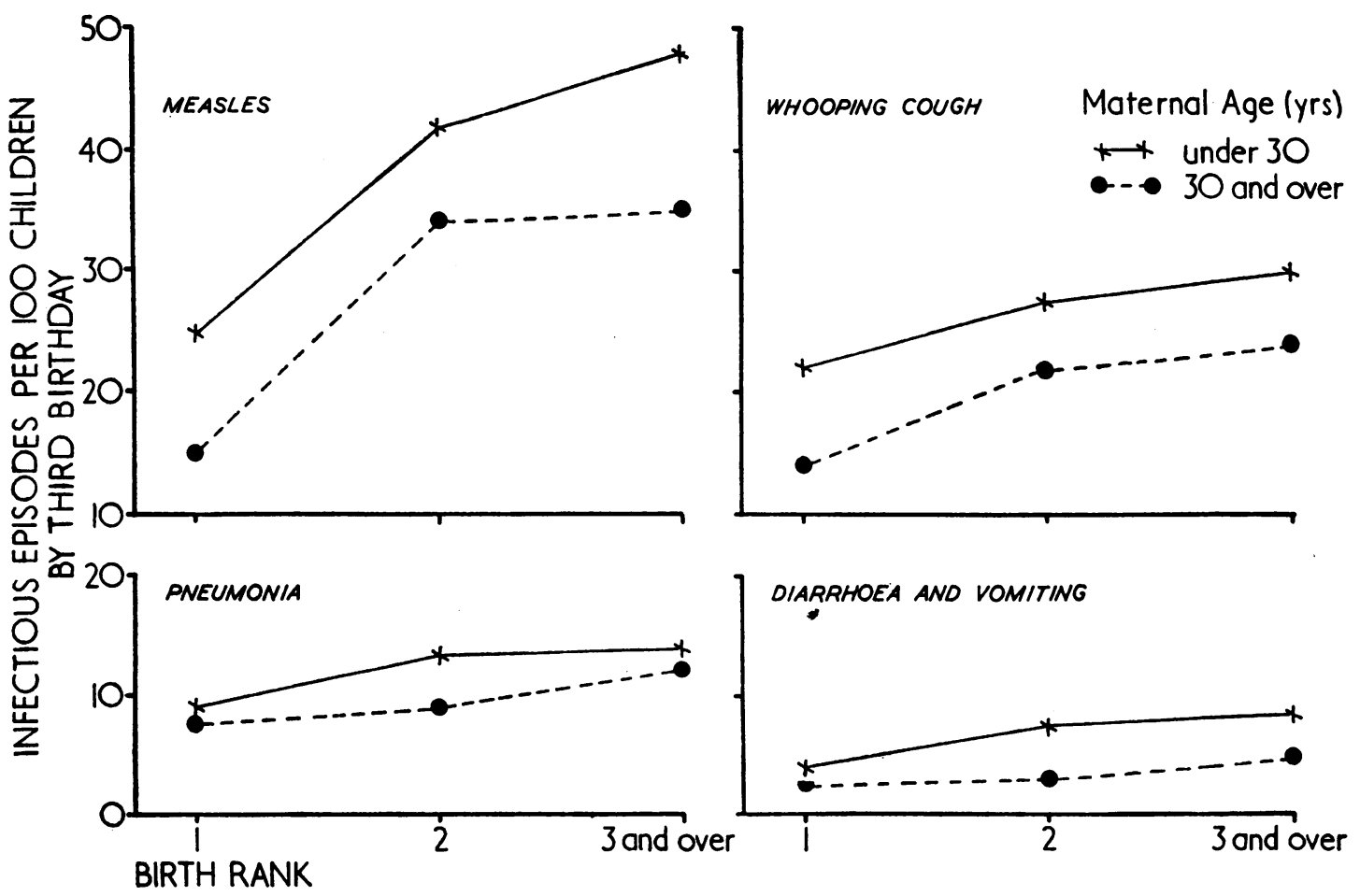

Fio. 5.-Incidence of certain infections in the first 3 years of life by birth rank and maternal age. 
is after all only one index of environment, and, chiefly because it takes no account of family size, not a particularly sensitive one. In association with maternal age and birth order much sharper differences can be demonstrated, and since both these variables are recorded in national statistics there seems no reason why they should not be incorporated to provide indices of social circumstances incomparably more sensitive than those now in use.

Finally, we may refer briefly to a possible interpretation of the striking increase in infant mortality, mainly from infectious disease, with increasing birth order. The greatly increased risks of death from infection experienced by late born children derive partly from

(a) the possibility of contracting infection, particularly at vulnerable ages, from older sibs,

(b) the poorer economic circumstances of large families, which may result in increased susceptibility to infection, and a higher case-mortality among the infected.

The higher case-mortality may be due both to lower resistance, and to less adequate medical attention. In general it seems probable that the increased risks of morbidity referred to under $(a)$ are experienced by all social classes, whereas the risks referred to under $(b)$ are confined to those families (of which there are still a substantial number) whose incomes are insufficient to provide necessities when there are several children. Expressed differently, risk of infection is raised if the family is large, but risk of death is seriously increased only if it is also poor.

We should also recognize that the association between mortality, birth rank, and economic circumstances is by no means the same for all infectious diseases. Measles and whooping cough are probably fairly accurately accounted for under (a) and (b) above. But tuberculosis is contracted mainly from adults, and would therefore be expected to be associated with birth order only in poor families and for the reasons referred to under $(b)$. Some types of gastro-enteritis appear to be of institutional origin, and are probably related to birth-rank only to the extent that frequency of hospital admission is determined by birth rank.

In another context these observations underline both the immense importance of family size in determining poverty, and the significance of family allowances as a contribution to the health of children. At a time when at least some of the gross differences in infant morbidity and mortality associated with income (as indicated by father's occupation) have been eliminated or reduced, it is important to recognize that it is still possible to identify groups of children whose risk of sickness and death is as high as that experienced by all children in England and Wales in the early years of the twentieth century. These are the late children of large families in poor circumstances, and they can readily be identified for statistical purposes as the late children of young mothers. (Here it is worth noting that the much publicized biological advantages of early conception are usually much more than offset by the social disadvantages which derive from the attempt to raise a large family on an inadequate income.) The case for family allowances is therefore strong, and having regard for the relative effectiveness of alternative social and medical services, it may be asked whether the scale of benefit should not be increased, and graduated according to the number of children, as suggested by the Royal Commission on Population (1949).

\section{SUMMARY}

A history of morbidity during the first 3 years of life was obtained from the mothers of 1,743 children born in Birmingham during 1947. It is shown that the incidence of infection was only slightly affected by the general standard of housing in the wards in which children were domiciled, but was sharply associated with maternal age and birth rank. Measles, for example, was more than three times more common among the third and later born children of mothers aged less than 30 , than among the first born children of mothers aged 30 and over.

It is suggested that the greatly increased risks of death from infection experienced by later born children derive partly from

(a) the possibility of contracting infection, particularly at vulnerable ages, from older sibs,

(b) the poorer economic circumstances of larger families, which may result in increased susceptibility to infection, and a higher casemortality among the infected.

It is noted, however, that the association between mortality, birth rank and economic circumstances is different for different infectious diseases.

We are indebted to Mrs. M. Hopper, who recorded the histories of morbidity. The research was assisted by a grant from the Birmingham University Students' Social Services Fund.

\section{REFERENCES}

Douglas, J. W. B. (1951). Popul. Stud., 5, 35.

Dykes, R. M. (1950). "Illness in Infancy". Leagrave Press, Luton. Grundy, F., and Lewis-Faning, E. (1953). British Journal of Preventive and Social Medicine, 7,31 .

Gibson, J. R., and McKeown, T.'(1952). Ibid., 6, 183.

Grundy, F. (1949). Med. Offr., 81, 144.

Lowe, C. $\dot{R}$., and Gibson, J. R. (1953). Britiish Journal of Preventive and Social Medicine, 7, 78.

Royal Commission on Population (1949). Report (Cmd. 7695) London, H.M.S.O. 